\title{
Gestión del multilingüismo y docencia indígena para una educación intercultural bilingüe en la Argentina*
}

\author{
Gestão do multilinguismo e docência indígena para \\ uma educação intercultural na Argentina
}

\section{Management of multilingualism and indigene teaching for an intercultural bilingual education in Argentina}

\section{Virginia Unamuno ${ }^{* *}$}

Resumen: El presente trabajo muestra los primeros resultados de una investigación sociolingüística en curso sobre la de educación intercultural bilingüe (EIB) en Argentina. $\mathrm{El}$ interés final de este trabajo es identificar algunos elementos que permitan dar cuenta del rol de las lenguas en los procesos sociales que involucran a la población indígena, poniendo en evidencia las formas en que los usos lingüísticos participan en la lucha por recursos materiales así como las representaciones sociales e ideologías lingüísticas que participan en la distribución desigual de dichos recursos entre grupos y al mantenimiento de desigualdades sociales. Para ello, se analiza el caso de una población - que llamamos El Algarrobo - en donde se forman docentes indígenas, los cuales son incorporados paulatinamente en las escuelas de la zona. En esta incorporación las instituciones educativas definen los roles de los docentes indígenas, así como el lugar de las lenguas en las mismas. Según muestra este trabajo, esta gestión de las lenguas está ligada a procesos de lucha social en los cuales las lenguas tienen un rol clave. La concepción del bilingüismo, las evaluaciones sobre las competencias lingüísticas de estudiantes y docentes indígenas, y las prácticas lingüísticas en las aulas ponen en evidencia la distancia entre los significados que circulan en los discursos oficiales sobre la EIB en Argentina y el sentido que obtienen éstos en las prácticas concretas en las aulas.

Palabras clave: Educación Intercultural Bilíngüe. Sociolingüística. Multilingüismo.

Resumo: O presente trabalho expõe os primeiros resultados de uma pesquisa sociolinguística a respeito da Educação Intercultural bilíngue (EIB) na Argentina. O interesse final deste trabalho é identificar alguns elementos que permitem compreender

\footnotetext{
* Este trabajo ha sido realizado en el marco del Proyecto PIP-2011-2013 del CONICET. Agradezco los comentarios de Alejandro Raiter y sus lecturas atentas a los borradores. También quiero agradecer a Leonor Acuña por su generosa predisposición en todo momento, a los docentes, estudiantes y directivos del CIFMA, y a los maestros bilingües de las escuelas de las zonas wichis que participaron desinteresadamente en este trabajo, el cual está dedicado a su esfuerzo cotidiano por construir una escuela mejor.
}

** Doctora en Filología. Universidad de Buenos Aires - CONICET. E-mail: <vir.unamuno@gmail.com> 
o papel das línguas nos processos sociais que envolvem a população indígena, pondo em evidencia as formas pelas quais os usos linguísticos participam na luta por recursos materiais e as representações sociais e ideologias linguísticas funcionais, em uma distribuição desigual desses recursos entre os grupos, colaborando para a manutenção de desigualdades sociais. Para tanto, se analisa o caso de uma população - que chamamos El Algarrobo - onde se formam docentes indígenas, os quais são incorporados paulatinamente nas escolas da região. Nesta incorporação, as instituições educativas, definem os papeis dos docentes indígenas, assim como o lugar das línguas nessas mesmas instituições. Assim, este trabalho mostra que a gestão das línguas está ligada a processos de luta social nos quais as línguas têm um papel chave. A concepção de bilinguismo, as avaliações acerca das competências linguísticas dos estudantes e docentes indígenas, assim como as práticas linguísticas nas aulas, revelam a distância entre os significados que circulam nos discursos sociais a respeito da IEB na Argentina e o sentido que estes ganham nas práticas concretas em sala de aula.

Palavras-chave: Educação Intercultural Bilíngue. Sociolinguística. Multilinguismo.

\begin{abstract}
Current paper presents the first outcome of an ongoing sociolinguistic research on bilingual intercultural education (EIB) in Argentina. The aim of this study is to identify some elements for an account of the role of language in the social process that involves native people by highlighting the manner in which language usage participate in the struggle for material resources and how social representations and linguistic ideologies are involved in the unequal distribution of resources among indigene groups and in the maintenance of social inequalities. The case of a population that called $E /$ Algarrobo has been analyzed. Native young people are trained as teachers and gradually incorporated in schools of the region. In such a process the educational institutions define the roles for native teachers and the place of languages. Results show that the management of languages is linked to the process of social struggle where languages have a key role. The conception of bilingualism, the assessments of native teachers with a competence of Spanish and classroom language practices evidence the distance between meanings in official discourses on EIB in Argentina and the meaning EIB has in day-to-day practice in the classroom and in the school.
\end{abstract}

Keywords: Intercultural Bilingual Education. Sociolinguistics. Multilingualism.

\title{
Introducción
}

En las últimas décadas, América del Sur en general y Argentina en particular están experimentando un cambio respecto al reconocimiento oficial de la diversidad lingüística y cultural. Esto se evidencia especialmente en algunos cambios legislativos y en la emergencia de políticas gubernamentales específicas en el campo de las lenguas, pero también en la circulación de un nuevo discurso en los medios de comunicación y en las escuelas que postula la Argentina como un país plurilingüe y pluricultural. En coherencia con estos cambios en la coyuntura político-discursiva, existen en la actualidad propuestas concretas que ponen de 
manifiesto la decisión política de incidir desde la administración pública en la gestión de las lenguas de la Argentina. Dice Trinchero (2010, p. 123):

Es indiscutible el hecho de que con la reafirmación de la democracia en el país, la reforma constitucional de 1994 se ha planteado un retorno a la política de reconocimiento de las poblaciones indígenas. Así, por ejemplo, dicha reforma constitucional define en su artículo 75, inciso 17, como atribución del Congreso de la Nación, reconocer la preexistencia étnica y cultural de los pueblos indígenas, garantizando el respeto a su identidad y el derecho a una educación bilingüe e intercultural.

En este contexto, la lucha histórica de las comunidades indígenas para el reconocimiento de sus derechos ancestrales sobre la tierra y por una educación de calidad para sus miembros, parece encontrar un mejor eco. Consideran, según diversas manifestaciones públicas, que es el momento de exigir el cumplimiento de las obligaciones constitucionales de los estados nacional y provincial, especialmente aquellas relativas a cesión de tierras, a la educación y a la inclusión social de sus miembros (UNAMUNO; RAITER, 2012).

Según los escasos datos oficiales, la población aborigen de la Argentina representa más del $2 \%$ de su población y agrupa los índices más altos de fracaso y deserción escolar (ACUÑA, 2002, 2010)ํ․ Además, se encuentra localizada en las áreas más pobres de aquel país, las cuales cuentan con la menor infraestructura en ámbitos importantes, como la salud y la educación.

Las poblaciones aborígenes, tradicionalmente agricultoras, cazadorasrecolectoras, pescadoras, etc. han debido cambiar sus formas habituales de subsistencia por diversas razones, entre las cuales destaca la presión de la explotación forestal y agraria, que en este siglo XXI se fundamenta en la exportación internacional de la soja y la madera (SLUZKY, 2008). En este conflicto de intereses, se presenta un creciente incremento de las migraciones internas que son fruto de la expulsión de los pobladores rurales de sus ámbitos tradicionales de vida. Actualmente, según el censo de población y vivienda de 2001, el 82\% de la población que se reconoce como indígena, habita en zonas urbanas, destacando las comunidades del Gran Buenos Aires y el Gran Rosario, las dos ciudades más pobladas de la Argentina. Dice Trinchero (2010, p. 134):

El más reciente proceso de expansión de la frontera agraria capitalista en Argentina genera una dinámica expulsiva de las poblaciones originarias con asentamiento rural, lo que implica un constante flujo migratorio campociudad. Esta dinámica, que va acompañada también del uso de agro-tóxicos

\footnotetext{
${ }^{1}$ Un dato interesante al respecto lo proporciona Ribeiro (2002), quien en un análisis sobre representaciones sobre Brasil y Argentina muestra que en términos relativos, la población indígena argentina es seis veces mayor que la brasileña. Estos datos contrastan fuertemente con el imaginario común que asocia a Argentina a un país "europeizante" y "monolingüe".
} 
a escala masiva, es la que explica, por un lado, el hecho de que un $82 \%$ de la población indígena argentina resida en ámbitos urbanos. También explica los límites para la regularización de los asentamientos de los pueblos originarios, cuyos derechos están garantizados constitucionalmente.

Tanto para los migrantes como para quienes aún habitan zonas rurales, la actividad productiva en la que participan es variada. Sin embargo, como gran generalización, cabe decir que los pobladores rurales combinan actividades productivas ligadas a la administración tradicional de la naturaleza y otras, ligadas al mercado y las reglas del capitalismo.

En este contexto de transformación económica relativa a las poblaciones indígenas se inserta el presente estudio, el cual se interesa específicamente por la formación de profesores indígenas y por la incorporación, luego, a las escuelas primarias públicas situadas en las zonas tradicionalmente indígenas. Estos nuevos maestros son actores clave en un conjunto de transformaciones en el orden social, económico y educativo - y también sociolingüístico - que, tal y como se mostrará, no está exento de tensiones.

El presente trabajo ${ }^{2}$ muestra los resultados de una investigación sociolingüística sobre la gestión de las lenguas en contextos de educación bilingüe indígena en Argentina. Se presentan, así, resultados de proyecto en curso: una primera aproximación a un conjunto de datos disímiles y recientes que aún deben procesarse y tratarse con cautela. Sin embargo, pareció interesante poner en relación estos primeros resultados con los cambios políticos y discursivos actuales en la Argentina. El interés final de este trabajo es identificar algunos elementos que permitan dar cuenta del rol de las lenguas en los procesos sociales que involucran a la población indígena, poniendo en evidencia las formas en que los usos lingüísticos participan en la lucha por recursos materiales y está sostenida por representaciones sociales funcionales a una distribución desigual de dichos recursos entre grupos y al mantenimiento de desigualdades sociales.

En un primer apartado, se presenta el contexto en el cual se sitúa este trabajo. A continuación, se describen las propuestas de Educación Intercultural Bilingüe en la Argentina, para poder situar concretamente, el tema de la formación de maestros indígenas. En tercer lugar, se presenta el caso de una institución de formación de docentes que llamaremos simbólicamente la Escuela de Maestros Bilingües para la Modalidad Aborigen (EMBMA), y se analizan datos relativos

\footnotetext{
${ }^{2}$ Esta investigación se desarrolla en el marco del proyecto PIP "Plurilingüismo y Educación Intercultural Bilingüe en El Sauzalito (Chaco)" , financiado por el CONICET. Quiero agradecer a los docentes y estudiantes del Instituto de Formación de Docentes Indígenas por su colaboración e interés por el presente trabajo; especialmente a su director, quien siempre ha estado abierto a consultas y propuestas. También quiero agradecer a los docentes bilingües que trabajan en el proyecto, y con quienes comparto horas de charla, mate y preocupaciones en torno a una educación más feliz. Finalmente, quiero dar las gracias a Carolina Gandulfo y a Alejandro Raiter por las lecturas a los diferentes borradores de este trabajo.
} 
a algunos impactos de la formación e incorporación de maestros indígenas en las escuelas públicas del norte de la Argentina (Provincia del Chaco). Luego, se analiza la gestión de las lenguas en las dinámicas sociales y escolares de la población wichi El Algarrobo, tomando como eje el análisis de las formas de evaluación social de las prácticas y las competencias lingüísticas de los docentes indígenas, y su relación con transformaciones sociales y educativas que implica la incorporación de estos docentes al sistema escolar. Por último, en unas líneas finales, se presentan reflexiones de índole teórica sobre el modo de abarcar la temática de las desigualdades educativas desde una sociolingüística de perspectiva crítica.

\section{Desde El Algarrobo}

Este trabajo es parte de un trabajo de investigación en la región de El Algarrobo (Provincia del Chaco, Argentina - ver mapa en anexo B, zona ubicada a casi 600 kilómetros de la capital provincial - Resistencia).

Los wichis son los pobladores originarios de la zona y el grupo mayoritario en El Algarrobo. Allí también viven personas criollas (de origen mestizo o inmigrantes de tercera generación en la zona) y personas blancas, forasteros venidos a la zona por razones laborales.

Se calcula que hay cerca de 40.000 wichis en la Argentina viviendo en las provincias argentinas de Salta, Chaco y Formosa. Se trata de una de las poblaciones indígenas más numerosas. El siguiente cuadro muestra su distribución:

Cuadro 1 - Población wichi

\begin{tabular}{|l|l|l|}
\hline \multirow{3}{*}{ Wichi } & Total & 40.036 \\
\cline { 2 - 3 } & Chaco, Formosa y Salta Provinces & 36.149 \\
\cline { 2 - 3 } & Otras provincias & 3.887 \\
\hline
\end{tabular}

Fuente: INDEC. Encuesta Complementaria de Pueblos Indígenas (ECPI) 2004-2005 elaborada por INAI.

Los wichis (que durante mucho tiempo fueron llamados despectivamente matacos) hablan una de las 13 lenguas indígenas que oficialmente se reconocen en el territorio nacional (MESSINEO; CUNEO, 2006). Si bien la mayoría de las lenguas que hablan estas comunidades están seriamente amenazas, el wichi es hablado por la inmensa mayoría de las personas que se consideran wichis ${ }^{3}$.

\footnotetext{
${ }^{3}$ Según la Encuesta Complementaria de Pueblos Indígenas (ECPI) que elabora datos recogidos entre el 2004 y el 2005, entre el 95\% y 93\% de las personas mayores de 5 años que se reconocen como wichis hablan esta lengua en la Argentina.
} 
Según Terraza (2002) y Vidal y Nercesian (2009), se trata de una lengua con gran vitalidad debido a la sostenida transmisión intergeneracional, a la existencia de hablantes monolingües (niños y ancianos), y a la ausencia de rasgos formales que denoten la amenaza interna de la lengua. Sin embargo, Terraza $(2002,2009)$ también muestra que hay enclaves en los cuales está amenazada.

Los wichis, antiguos cazadores-recolectores, actualmente basan su economía en las artesanías, la pesca, la caza de pequeños animales y la recolección de miel y frutos del monte. Muchos de ellos también trabajan en la agricultura y la ganadería, como empleados temporales. Desde hace algún tiempo, se han ido incorporando a la educación (como auxiliares bilingües), al mundo sanitario (como enfermeros) y a la administración pública, ocupando diversos puestos en las instituciones locales. Sin embargo, hace falta considerar también que la mayoría de las familias wichi, debido especialmente a la ocupación de sus tierras por parte de personas blancas para el cultivo de la soja y la ganadería, han debido abandonar sus formas tradicionales de trabajo y actualmente se sustentan sobre la base de las ayudas gubernamentales incluidas en los planes sociales (UNICEF, 2009).

Si bien existen en la zona servicios educativos públicos y gratuitos, el porcentaje de wichis que terminan la educación obligatoria es muy bajo. Según la citada encuesta (ECPI 2004-2005), el 19,9\% de los wichis mayores de 14 años no ha asistido a la escuela y sólo el 16,2\% tiene terminada la escuela primaria. Estos datos contrastan con los datos a nivel nacional que muestran que el $82,1 \%$ de los argentinos ha recibido instrucción formal de algún tipo (INDEC, 2001).

Según el estudio coordinado por UNICEF (2009), la falta de escolaridad de los niños wichis se debe principalmente a la ausencia de recursos de las familias, a la escasez de becas y a la gran distancia entre la escuela y los lugares de residencia de las familias. También cabe mencionar en este caso la falta de conocimiento de la lengua wichi y las actitudes discriminatorias por parte de los docentes blancos, lo que hace de la escuela un lugar hostil, según diversos testimonios recogidos en el citado informe.

Las escuelas de la zona se caracterizan por implementar en la práctica un modelo de educación lingüística orientado hacia el aprendizaje del español ${ }^{4}$, lengua vehicular de la enseñanza en la Argentina. Debido a la presencia de niños monolingües en el inicio de la escolaridad, todas las escuelas primarias de la zona cuentan con un docente indígena en los primeros cursos; es decir, en el preescolar (4 y 5 años) y en el primer ciclo de primaria (6 y 7 años) (FERNÁNDEZ; GANFULFO; UNAMUNO, 2012). Parte de estos docentes

\footnotetext{
${ }^{4}$ A lo largo de este trabajo, las palabras "español” y “castellano” se utilizarán como sinónimos.
} 
no están titulados para el ejercicio de la docencia. Se trata de personas idóneas que auxilian o asisten a los docentes no indígenas durante las clases. Esta asistencia, normalmente descrita como "traducción", está pensada para garantizar el acceso de los niños al conocimiento del español, lengua que será único medio de instrucción a partir de los 8 años hasta el secundario. Son excepcionales los docentes bilingües que ejercen la docencia más allá del primer ciclo de educación primaria, y sólo en una de las escuelas secundarias de la zona se cuenta con docentes indígenas, quienes tienen a su cargo la enseñanza de lengua y cultura wichi como asignatura.

\section{La educación intercultural bilingüe}

La educación intercultural bilingüe (en adelante, EIB) en la actualidad en Argentina se entiende de diversas maneras, incluso contradictorias: a. un conjunto heterogéneo de propuestas muchas veces aisladas y dependientes de iniciativas particulares, tendientes incorporar la lengua y otras prácticas culturales de los pueblos originarios a la institución escolar. Esta manera de entender la EIB es la que describen los documentos oficiales en los cuales se recopilan experiencias y propuestas de aula en las cuales trabajan docentes o donde se escolarizan niños indígenas; b. las características del contexto de intervención educativa, marcado por la presencia mayoritaria de población aborigen; c. un conjunto de propuestas que emergen como respuesta institucional al reclamo de las organizaciones indígenas para que sean reconocidos plenamente sus derechos a una educación de calidad y a la presencia de sus prácticas culturales y lingüísticas en la institución escolar (SERRUDO, 2010).

Tal y como se ha señalado en otras oportunidades (UNAMUNO, 2011), la visibilidad actual de estas propuestas, experiencias y características contextuales se enmarcan en cambios legislativos y políticos importantes que se produjeron desde la década de los 80 y 90, y que se visibilizan especialmente en las leyes provinciales sobre temas indígenas, en las reformas de las Constituciones provinciales, en la reforma de la Constitución Nacional y en las últimas leyes de educación (PETZ, 2010; BENGOCHEA; SARTORI, 2010). Esta nueva visibilidad de lo indígena en general y de la EIB en particular no es ajena a un conjunto de cambios estructurales de índole internacional y regional, que se acompañan con la circulación de un nuevo discurso oficial en el cual lo multicultural, la diferencia y la diversidad se establecen como parte de la agenda política y económica.

Como se señaló, si bien estos cambios legislativos son recientes, la lucha de pueblos originarios para la incorporación de su lengua y otras prácticas culturales propias a los procesos de escolarización tiene una larga historia 
(LÓPEZ; KÜPER, 2004; NOVARO, 2004; HIRSCH; SERRUDO, 2010; ZIDARICH, 2010, entre otros).

En Argentina, como en Latinoamérica en general, uno de los grandes problemas de la efectivización de la EIB se encuentra en la poca disponibilidad de recursos humanos bilingües formados para la educación. Los jóvenes indígenas han sido sistemáticamente excluidos del sistema escolar, por lo cual, pocos de ellos cuentan con el título que hace posible su ingreso a la educación terciaria en la cual se forman los docentes en la Argentina. Por ello, durante las últimas décadas, las propuestas de EIB se caracterizaron por un modelo de gestión mixta de las aulas, a través de la co-presencia de un docente no indígena y un docente indígena, el cual actuaba en calidad de auxiliar docente y se le reconocía la categoría de idóneo (sin título oficial). Zidarich (2010) narra en su trabajo las dificultades de este tipo de experiencias, las cuales no dejan de estar marcadas por las jerarquías culturales y sociales entre ambos tipos de docentes.

En la provincia del Chaco, contexto de la presente investigación, estos primeros docentes indígenas que se incorporaron al sistema educativo fueron considerados en las políticas educativas y lingüísticas como parte de una etapa de transición, orientada a esperar que los jóvenes de las comunidades tuvieran acceso a la educación terciaria. Esta incorporación, así como el incentivo público a la formación de docentes indígenas, fue promovido por la Ley del Aborigen Chaqueño sancionada en 1987. Dice el capítulo relativo a la educación:

CAPITULO III

DE LA EDUCACION Y CULTURA

ARTÍCULO 13: Se reconocen a las culturas y lenguas toba, wichi y mocovi como valores constitutivos del acervo cultural de la Provincia.

ARTÍCULO 14: Los aborígenes tobas, wichis y mocobies tienen derecho a estudiar su propia lengua en las instituciones de enseñanza primaria y secundaria de las áreas aborígenes.

ARTÍCULO 15: La educación impartida en los establecimientos escolares que atiende el universo indígena se realizará en forma bicultural y bilingüe.

ARTÍCULO 16: El Consejo de Educación programará acciones directas tendientes a promover el acceso del indígena a los distintos niveles educativos, sobre la base de:

a) Dotar de infraestructura educacional básica a las comunidades aborígenes.

b) Adaptación de los contenidos curriculares conforme a la cosmovisión e historia de los pueblos aborígenes que habitan en la Provincia.

c) Instrumentación de la estructura pedagógica incorporando las habilidades y conocimientos de los pedagogos indígenas para la enseñanza de las prácticas tradicionales.

d) Perfeccionamiento docente de los educadores de indígenas sobre la realidad cultural de los mismos y sus lenguas. 
e) Dar prioridad a la formación de docentes indígenas a través de planes adecuados para tal cometido.

f) A efectos del período de transición se formarán e incorporarán auxiliares docentes aborígenes.

g) Hacer efectivos programas de alfabetización para adultos indígenas tomando en consideración su dialecto y su cultura.

h) Difundir a través de publicaciones, cátedras y de los medios de comunicación social el patrimonio cultural indígena y su aporte a la cultura nacional.

i) Fomentar las artesanías indígenas que preserven su autenticidad considerándolas como fuente de trabajo y expresión cultural de nacionalidad. (CHACO, 1987).

Esta ley tuvo y tiene un impacto muy importante en las dinámicas educativas que atañen a las poblaciones indígenas en el Chaco, tal y como se mostrará a continuación.

\section{La EMBMA y la formación de maestros indígenas}

En el marco de la ley y frente a la necesidad de contar con docentes bilingües titulados, las comunidades indígenas comenzaron a exigir el apoyo por parte de los estados provincial y nacional para que sus miembros fueran formados para ejercer la docencia en las comunidades. Así, a finales de los 80 se crea en la provincia del Chaco un centro de formación de docentes indígenas.

Según las comunidades indígenas moqoit, qom y wichi, este instituto tiene el mandato de dichas comunidades para capacitar a sus jóvenes para ejercer la docencia primaria. Por ello, para ingresar a dicho centro educativo, se necesita de un aval de la autoridad comunitaria (normalmente un cacique o un anciano referente) que confirme la pertenencia del candidato a alguna de las citadas comunidades indígenas. Este aval les permite, además, recibir una beca mínima para pagar los materiales de estudios. Actualmente, han egresado del EMBA unos 200 docentes.

En el año 2008, los wichis de la zona de El Algarrobo demandan la creación de una sede en sus comunidades, de manera que sus jóvenes puedan continuar allí sus estudios sin necesidad de desplazarse a la ciudad. En esta zona, si bien hay numerosas escuelas primarias y secundarias, no había, hasta la creación de la EMBMA, ninguna oferta formativa para los jóvenes que acabaran la educación secundaria. Ni para los indígenas ni para los no indígenas. Como cuenta su director, la creación de esta institución no fue fácil: 
Fragmento 1 (Participantes: LUKAS: docente del EMBMA y INV: Investigadora $)^{5}$

LUKAS: es como que todas las cosas que se crean en esa zona pertenecen a cierto grupo de gente $\backslash$ y la otra tiene que seguir siendo sometida_tiene que seguir siendo_ inculta $\backslash$ tiene que seguir siendo_no tener posibilidades de estudios $\backslash \mid$ entonces una vez que tienen un_un logro $\backslash \mid$ que es logro de sus ancianos $\backslash$ de los pedidos de las comunidades $\backslash \mid$ y en donde realmente necesitan de ese espacio porque preparar un maestro bilingüe_ un profesor bilingüe es eso $\backslash \mid$ ellos tienen que estar juntos $\backslash \mid$ discutir juntos $\backslash$ CON el asesoramiento y con la parte profesional que les dan los_los profesores $\backslash$ tanto wichies como no wichies $\backslash$ | entonces - | es esa la_lo_lo gracioso $\backslash$ | que esta gente que por muchos años está ahí en la zona y que creen que siempre manejaron todas las cosas \pueden seguir haciendo de la gente que está ahí $\backslash$ gente sometida $\backslash \mid$ entonces esa es una preocupación $\backslash$ y así demuestran con esas denuncias con esas cosas $\backslash$ | cuál es el sentimiento de ellos $\backslash$ | que a pesar de los años no se dieron cuenta cuál es la realidad del lugar $\backslash \mid$

Lukas es un profesor no indígena que vive y trabaja en El Algarrobo. Según relata en este fragmento de entrevista, la apertura de la EMBMA creó muchas incomodidades, algunas de las cuales derivaron en denuncias legales por discriminación, hacia los blancos; ese grupo de personas que en el relato de Lukas, "a pesar de los años no se dieron cuenta cuál es la realidad del lugar".

Esta realidad, podríamos decir, está fuertemente marcada por la presencia minoritaria de un grupo de personas provenientes de diferentes zonas de la Argentina, no indígenas, denominados blancos, que ejercen allí tareas diversas en las instituciones públicas y en las empresas privadas. Médicos, políticos, administrativos, directores, maestros y profesores de escuela, enfermeros, etc. conviven con los wichis en un territorio complejo, alejado de los centros urbanos y comunicado sólo por caminos de tierra que se hacen intransitables en las épocas de lluvia. Allí viven durante gran parte del año, en casas subvencionadas por el estado. Por trabajar allí, el mismo estado les compensa con un plus salarial, que duplica muchas veces lo que ganarían en otra destinación. Se trata, según dicen los estatutos, de una zona desfavorable.

\footnotetext{
${ }^{5}$ Los fragmentos 1 y 2 son parte de una entrevista a un docente no indígena de la EMBMA en El Algarrobo en febrero de 2011. Los fragmentos 3, 5 y 6 han sido extraídos de transcripciones de entrevistas, realizadas a las y los directores de las escuelas de la zona. El fragmento 4 es parte de la transcripción de una clase realizada entre una maestra no indígena y una docente indígena en un primer grado de una escuela primaria de la zona. La simbología de transcripción figura en el anexo.
} 
Prosigue Lukas:

Fragmento 2 (Participantes: LUKAS: Profesor EMBMA; INV: Investigadora)

LUKAS: hoy vos me decías del tema del desplazamiento al maestro blanco $\backslash \mid \mathrm{xx}$ es la realidad $\backslash$ y es verdad $\backslash \mid$ pero también sabemos que el sistema educativo tiene que ir absorbiendo esa cantidad de maestros que están en un lugar que no están a gusto \| un maestro blanco no quiere_yo pienso que el que siente la profesión no quiere que sus chicos no lo entiendan_ que sus chicos no avancen $\backslash$ | y el sólo hecho de no saber manejar la lengua ya es una traba para que por ahí no avancen lo que podrían avanzar $\backslash$ | y la solución te digo porque_es una zona lejos \todos los maestros profesores llegan desde muy lejos \}

INV: y están a gusto? | porque hay una variable de tipo económica \no/ |que ganan_

LUKAS: se gana más \se gana bien $\backslash \mid$ ¿qué pasa?| el sistema nos permite muchas cosas $\backslash$ como licencia como_ como falta justificada $\backslash$ como días de paro $\backslash \mid$ porque un docente cuando sale [del Algarrobo] $\backslash$ no sale un día o dos $\backslash$ sale una semana y cuando menos $\backslash$ si no son dos semanas que el chico perdió \| y con el maestro bilingüe es de ahí \no tiene la necesidad de ir a ver sus padres $\backslash$ su familia $\backslash$ entonces es una solución $\backslash \mid$ si la vemos desde otro lado \que por ahí el maestro blanco se va_yo creo que tienen que ir absorbiendo otras regiones otras zonas $\backslash$ |

INV: ¿cuál es la perspectiva del maestro blanco? ¿ ¿cómo lo ve? |

LUKAS: el blanco lo ve así \| de ahí \existe cierta resistencia ha_ hacia lo que se llama bilingüe desde que llegó la EMBA ahí por esa situación\| porque saben que son la competencia $\backslash$ y saben que van a ocupar lugar que por ahí vos pensabas cinco años atrás que era una _ una cosa imposible pensar en eso \|

Tal y como relatan Lukas y su entrevistadora, el proyecto de formar maestros bilingües e indígenas no está exento de tensiones. Entre ellas, las que involucran a los maestros no indígenas, los "viejos maestros". Para ellos, según relata la entrevista, el proyecto en general y los maestros indígenas en particular son vistos como una amenaza a los privilegios de los que disfrutan históricamente - un buen sueldo, vivienda barata, excedencias varias, etc. Según Lukas, esta resistencia "bacia lo que se llama bilingüe" es en definitiva una resistencia a una nueva distribución de recursos materiales, hacia la posibilidad que aquellos que siempre han sido "sometidos, incultos" (fragmento 1) dejen de estarlo. Según Lukas, estos privilegios - como por ejemplo, el poder ausentarse varios días de su trabajo sin necesidad de justificarlo - perjudica a los niños wichis y es un claro ejemplo de la plusvalía que ofrece la alternativa de maestros autóctonos. 
Claro está que, como Lukas, muchos actores sociales del lugar están seguros que la incorporación de estos nuevos maestros al sistema educativo será positiva para el mismo. Sin embargo, esto parece dificultado no sólo por la actitud adversa de una parte importante de los directivos y los docentes tradicionales, sino por la falta de un apoyo económico por parte del estado, por lo cual, los estudiantes del EMBMA tienen serias dificultades para continuar y terminar sus estudios (UNAMUNO, 2012). Las becas indígenas son escasas y su importe, cuando consiguen percibirlo, no alcanza a cubrir ni siquiera los gastos de materiales de estudio. Dispersos en el monte y habitantes de zonas alejadas por decenas de kilómetros de El Algarrobo, si consiguen terminar allí sus estudios secundarios, proseguir con los estudios terciarios se hace muy complicado. Además, por el tipo de organización social de los wichis, al terminar la escuela secundaria muchos de los jóvenes son padres y madres de familia (UNICEF, 2009).

No sólo los estudios son complejos para los jóvenes indígenas. La incorporación de los nuevos maestros a la escuela pública de la zona, de tradición monolingüe y perspectiva no indígena, no es fácil. Muchas veces, como se puede deducir de los fragmentos citados, los "viejos maestros" - no indígenas - son reacios ceder el lugar de quien enseña a una persona aborigen. Esta actitud parece sostenida también por la administración de la educación: es notorio, en este sentido, que no exista un programa que garantice la inserción de estos nuevos maestros al sistema escolar ni, en el caso de haber obtenido allí una vacante, algún tipo de seguimiento institucional por parte de la administración estatal o provincial que pueda acompañarlos y asistirlos durante los primeros años.

Esto sorprende especialmente si se considera, tal y como postula la legislación en materia de educación bilingüe y su reglamentación, que el estado espera de estos maestros transformaciones educativas fundamentales, como pueden ser una mayor inclusión de los niños indígenas en la escuela, la mejora de los resultados escolares y el aumento de los niveles de escolarización entre la población indígena. Dice la Resolución no 119/10 del Consejo Federal de Educación:

Desde esta modalidad se entiende que la Educación Intercultural Bilingüe, en tanto parte del sistema educativo, tiene la responsabilidad de tender al logro de una relación pedagógica constante y significativa con alumnos y alumnas de las distintas comunidades y pueblos indígenas, con su entorno de pertenencia, para de ese modo llevarla a la práctica con el fin de aportar a la construcción de nuevos modos de acceder a conocimientos y prácticas escolares necesarios en cada nivel para contribuir al mejoramiento de la vida de estos pueblos. (ARGENTINA, 2010, p. 2). 
Los nuevos docentes indígenas parecen, así, tener a su cargo transformaciones educativas importantes que atañen a la educación de la población aborigen, la cual, según muestran los datos censales (ECPI-2004/5), presentan el mayor índice de fracaso y abandonos escolares, así como el mayor índice de sobreedad.

Sin embargo, tal y como se ha explicado, la inexistencia de una política gubernamental que garantice la inserción de estos docentes en las escuelas y un acompañamiento a su práctica docente inicial, los deja solos en los contextos en donde la educación tiene sus peores condiciones no sólo materiales, sino especialmente simbólicas, relativas a las representaciones sociales negativas hacia la enseñanza en y de lenguas indígenas, y a la idoneidad de los docentes indígenas para ejercer la docencia. Tal y como señala Serrudo (2010), la formación de estos docentes ha sido permanentemente criticada y sus competencias han sido descalificadas por los docentes y directivos de la escuela tradicional. Como mostraremos a continuación, en estos procesos de desacreditación, las competencias lingüísticas han sido clave.

\section{Lenguas: otros recursos en disputa}

En el marco de las transformaciones que relata este trabajo y de las tensiones que generan la presencia de nuevos actores en instituciones educativas que tradicionalmente los excluía, las lenguas aparecen como un recurso también en disputa. Sin embargo, se trata de una cuestión sutil, poco explícita, que hace necesaria una investigación precisa que aún estamos empezando.

Quizá un punto de partida para poder describir el lugar de las lenguas en estas transformaciones podría radicar en comprender, por un lado, el rol que se espera de los docentes indígenas bilingües en las escuelas y, por otro, la manera en que allí se gestionan las lenguas y se evalúan las competencias lingüísticas de los docentes.

El término "gestión de lenguas" es empleado aquí para hacer referencia a las relaciones entre lenguas y variedades que pueden ser descritas atendiendo tanto a aspectos micro, meso y micro sociolingüísticos. A diferencia de otras miradas sobre las relaciones entre lenguas en contextos multilingües, en este trabajo se considera clave el relevamiento de las evaluaciones que realizan diferentes actores involucrados en dichos contextos sobre las prácticas lingüísticas. Se trataría, en definitiva, de recoger "voces" diversas a través de un trabajo etnográfico que permitiese construir un acercamiento holístico a las formas en que los usos lingüísticos son valuados, los valores que adquieren en los procesos sociales que se analizan, y las consecuencias que la jerarquía entre estos valores q tienen para los hablantes. Son, en definitiva, voces en disputa, en lucha por imponer un valor 
(VOLOSHINOV, 1992) a las prácticas y las competencias que están involucradas las lenguas en diferentes instancias que este trabajo pretende explorar. Pero también, el análisis pretende relacionar estos procesos de evaluación social con otros procesos sociales, ligados más evidentemente a cuestiones materiales, como pueden ser las relativas a la ocupación de lugares de trabajo y la obtención de un salario.

\section{El español como recurso simbólico de acceso}

Tal y como señala MALDONADO (2008) y también SERRUDO (2010), y de acuerdo a nuestros registros de clases en diferentes escuelas de El Algarrobo, desde la perspectiva dominante la presencia del docente indígena se justifica en su papel de intérprete y traductor de persona que tiene a su cargo el facilitar al acceso a la lengua oficial, el español.

En el siguiente fragmento, la directora de una escuela primaria de la zona describe, según su perspectiva, el rol del docente bilingüe en las aulas:

Fragmento 3 (Participantes: DIRE555: Directora escuela 555; INV: investigadora)

1. DIRE555: eso_tengo un solo maestro intercultural que

2. nosotros_ nosotros teníamos el cargo con un maestro bilingüe

3. intercultural_que era de aquí de la zona_del paraje $\backslash \mid$ nacido

4. aquî $\backslash$ renunció y se fue a trabajar más cerca con su señora $\backslash$

5. y este- $\mid$ de ahí no podíamos conseguir maestros bilingües con

6. título \porque ninguno tenía el título hasta que el año

7. pasado se recibió un grupito y vino ahora a trabajar $\backslash<0>$

8. INV: ¿trabaja acá?

9. DIRE555: trabaja acá \ y el está trabajando acá hace más o

10. menos un mes que está trabajando $\backslash \mid$

11. INV: ¿y vos cómo ves la inserción de los maestros bilingües

12. Acá? \

13. DIRE555: sí \y los veo \yo siempre fui la de pelear mucho

14. po_por los bilingües y los auxiliares $\backslash \mid$ yo cuando asumí el

15. cargo directivo encontré un nivel muy bajo de educación

16. especialmente los aborígenes $\backslash \mid$ pero el tema es que no nos

17. entienden a nosotros $\backslash \mid$ entonces es imposible que nosotros

18. queramos explicarle vos les enseñas a sumar restar

19. multiplicar dividir y está de diez $\backslash \mid$ lee y escribe $\backslash$ pero no

20. le pidas que te comprenda una lectura $\backslash \mid$ o no le pidas que te

21. hagan algo más porque no nos entienden lo que nosotros les 
22. explicamos $\backslash \mid$ especialmente los chiquititos $\backslash \mid$ los más grandes

23. sí $\backslash \mid$ pero los de primer ciclo no entienden $\backslash \mid$ lo mismos los

24. de jardín $\backslash \mid$ no nos entienden $\backslash$ | y más si viene una maestra

25. nueva y les habla seguido \| están en el muere \están en el

26. muere $\backslash \mid$ no entienden nada $\backslash \mid$ entonces no es que no aprenden

27. porque el maestro no les enseña o porque ellos no tengan

28. interés $\backslash$ sino porque no los entienden_no los entienden $\backslash \mid$ si

29. no te sabés expresar con ellos-

Tal y como describe esta directora, el docente indígena es importante porque permite el acceso de niños y niñas a la comprensión de los contenidos y prácticas escolares (líneas 20 y 21), especialmente en el área de lengua. Todos ellos en español. Como también se desprende de la entrevista, esta directora como la mayoría de los directivos entrevistados - considera que el rol del docente bilingüe se justifica especialmente en el primer ciclo de educación primaria entre los 6 y los 9 años -, y en jardín de infantes, donde los niños no entienden.

Es interesante esta entrevista (ver subrayado) por dos razones: por un lado, la diferencia entre el nosotros (los no indígenas) y el ellos (los indígenas) está claramente marcada en toda la entrevista, al igual que la diferencia entre el yo (la directora) y el nosotros (la institución). Sin embargo, los dos nosotros se confunden durante la entrevista, hecho que permite suponer que se está hablando de una institución que se describe as así misma en la lógica de oposición nosotros-ellos; es decir, opuesta a ellos, los "aborígenes" (línea 16).

La "escuela no indígena" parece esperar delos docentes bilingües participen en el desarrollo de las competencias activas y pasivas en español por parte de los niños indígenas, y que lo hagan en la primera etapa de la escolarización. Por ello, según los datos que hemos relevado (UNAMUNO, 2011), la gran mayoría de los docentes bilingües graduados en el EMBMA se encuentra trabajando en el ciclo inicial de educación primaria. Fuera del inicio de la escolaridad, ni directivos ni supervisores de la educación consideran necesario no sólo la presencia del docente bilingüe, sino tampoco el uso de las lenguas indígenas en las aulas (UNAMUNO, 2011). Además, tal y como mencionamos, las competencias en lengua española de los docentes indígenas no son considerada suficientes para el final de la escolarización primaria, en donde se supone puede seguirse la escolaridad en "la" lengua propia de la misma, el español. En esos cursos, docentes y directivos no indígenas están de acuerdo que es preferible un docente blanco, que si bien desconoce el contexto y las pautas culturales de los wichis, "está más preparado para enseñar en castellano" (directora escuela de El Algarrobo).

En este proyecto escolar, cabe preguntarse cuál es el modelo de castellano que se considera propio y adecuado para las escuelas. Se trata, según los datos 
que se desprenden de entrevistas y observaciones de clases, de un modelo de lengua escolar idealizado, ligado a la normativa y desligado del contexto real de uso. Este español escolar contrasta cotidianamente con aquel que es propio de las prácticas verbales concretas de los hablantes de la zona de contacto (PRATT, 1992/2010), marcadas principalmente por el uso alternante de más de una lengua, por el uso de variedades mixtas y por ser parte de procesos de hibridización verbal constantes. En este enfrentamiento, el español idealizado y "correcto" (la norma) se activa en los juicios negativos sobre las formas de hablar castellano de los indígenas, entre los cuales están, justamente, los "nuevos maestros" (indígenas) y también, los estudiantes de la EMBMA que realizan las prácticas docentes en las escuelas primarias (UNAMUNO, 2011).

En síntesis, si bien las competencias en lengua wichi son exclusivas de los miembros de las comunidades aborígenes (las personas no indígenas que habitan en la zona estudiada desconocen esta lengua), la lengua castellana es compartida por unos y otros. Así, creemos, el castellano define un terreno conflictivo, en el cual puede observarse de forma clara la lucha en la cual participa el lenguaje. El castellano "normativo", "escolar", "correcto" parece el capital simbólico en disputa, que docentes no indígenas pretenden acaparar para sí en esta lucha por poder decir y poder significar.

Como se dijo, esta crítica a los docentes indígenas por su español "no correcto" es común y deja entrever una perspectiva normativista sobre la lengua, ajena a la realidad del contacto entre lenguas que caracteriza la zona estudiada. Sin embargo, esta ideología lingüística (de la estandarización - MILROY, 2001) es funcional a la lucha simbólica en que se encuentran implicados docentes indígenas y no indígenas, ya que participa activamente en los procesos de evaluación negativa de los docentes indígenas y sus prácticas educativas.

La ideología de la estandarización hace eco en el anonimato tal y como lo entiende, por ejemplo, Woolard $(2007,2008)$. Según esta autora, las lenguas hegemónicas basan su autoridad lingüística en la ideología del anonimato; es decir, en la idea que estas lenguas están naturalmente desligadas de procesos sociales e históricos, incluso territoriales. Presentada fuera de la lógica de las relaciones y tensiones sociales, las lenguas hegemónicas - como el español, en este caso - son presentadas en el discurso dominante como fuera de la lucha simbólica que involucra a sus usuarios. Dice Woolard (2008, p. 180)6:

Dentro de una ideología del anonimato, la autoridad lingüística de una lengua estándar común no es localizada, sino desarraigada y universalista. De acuerdo con este razonamiento, las lenguas públicas pueden representar a todos, y ser usadas igualmente por todos, precisamente porque no pertenecen a nadie en particular. Las lenguas públicas se posicionan como universalmente abiertas y disponibles para todos.

\footnotetext{
${ }^{6}$ La traducción es mía.
} 
En este proceso de "anonimización" de la lengua la escuela juega un rol clave. Es a través de instituciones como ésta que se borra la historia de emergencia de la lengua estándar, normativa y "correcta", y se desliga su origen en el habla de grupos sociales específicos. A través de la escuela y los medios de comunicación, la lengua estándar deviene la lengua del "no-lugar", la lengua común, cuyo acceso está democráticamente garantizado. Si no se produce este acceso, el problema no está en la lengua - ni en los procesos sociales que la configuran -, sino en los usuarios (quienes son incompetentes, incultos, poco educados, etc.).

Para los estudiantes del EMBMA y sus egresados, esto no es tan claro. Según los datos que hemos recogido a través de entrevistas y de textos escritos, para ellos el español está socialmente jerarquizado en la zona. Lejos de representar una voz anónima, para estos jóvenes representa la voz de los sectores dominantes en la zona. Médicos, funcionarios, terratenientes, abogados, etc. son para estos jóvenes los portavoces del "castellano de las palabras técnicas" (UNAMUNO, 2011), una variedad de lengua ligada a las prácticas simbólicas dominantes entre las cuales están los estudios superiores y la docencia. Este castellano está colocado entre otros: los propios de las personas de la zona que no ocupan los lugares sociales de poder y los propios de los hablantes bilingües, "mezclados". La escuela, a través de sus prácticas de enseñanza y de evaluación de alumnos y docentes, participa en la consolidación de esta jerarquía y en su reproducción.

\section{Gestión de las lenguas y construcción de los lugares en el aula}

Como se ha señalado, en el imaginario de la zona el rol del docente indígena está ligado a la traducción. Su participación en las aulas obtiene sentido en tanto que garantía de la compresión de la comunicación entre alumnos aborígenes y docentes blancos, así como los contenidos curriculares escolares en castellano.

La traducción es la actividad que mayormente se espera del docente indígena, y es en muchos casos el lugar desde dónde se lo evalúa. En el imaginario de docentes blancos y directivos, se trata de una actividad fácil, del "sencillo" traspaso de una lengua a otra, pero también una herramienta de control por parte de los no indígenas de lo dicho en una lengua que todos ellos desconocen. Por ello, durante las clases en las cuales están presentes tanto el docente indígena como el docente blanco, este último planifica la intervención del primero, controlando de forma minuciosa su participación, a través del control de la sucesión de turnos de habla, sea de forma explícita o a través 
del contacto visual. El siguiente fragmento correspondiente a una clase la cual participa un docentes indígena (MW) y una docente no indígena (MB) ilustra este proceso.

Fragmento 4 (Participantes: MB: maestra blanca; MW: maestra wichi; JU: Juanito -alumno-)

[Angélica (MB) escribe en la pizarra unas frases para leer junto a unos cuadros que separan sílabas. Pide a los niños que pasen a completar los cuadros con las sílabas de las palabras subrayadas en las frases]

1. MB: $\{($ a Junito)ah? $<\mathrm{XX}>$ qué dice acá Juanito?\}

2. JU: mate $\backslash||$ MB: muy bien $\backslash \mid$ ma::te $\backslash \mid$ *Jazmín vuelve a su banco*

3. JU: casi me caigo $\backslash \mid$ [rie] MB: bueno $\backslash \mid$ MB: Bryan $\backslash \mid$ ¿querés pasar a marcar la segunda? | pasá \|

4. MW:: APASA $\backslash \mid$ BRYAN $\backslash \mid M B$ : decile que marque arriba y abajo $\backslash *$ MW se desplaza del lateral al centro del aula*

5. MW:: EH| LAPASACHE ATHANA $\backslash \mid *$ Bryan pasa a la pizarra con poco interés*

En este breve fragmento puede verse como la docente no indígena indica a la otra docente cuándo intervenir, solicitando una traducción de su intervención anterior que por alguna razón considera opaca para los alumnos. En el control de la sucesión de turnos que ejerce el docente blanco en la conversación (MARTIN-JONES; SAXENA, 1996), en la gestión de la "agenda de clase" (CAZDEN, 1991), en el rol que ocupa en la abertura y cierre de episodios discursivos (SINCLAIR; COULTHARD, 1975), se describen las asimetrías implicadas en estas clases bilingües, en donde las voces de ambas docentes no tienen el mismo valor.

Como las competencias en español, las competencias bilingües de los docentes indígenas también son evaluadas por la institución. Si bien pareciera que son valuadas positivamente por directivos, docentes y familias no indígenas, las prácticas escolares que hemos registrado muestran más bien que el bilingüismo obtiene un valor exclusivamente en función de su descripción como "paso previo" al castellano, como puente hacia las competencias que realmente valen; es decir, aquellas en español. La traducción es, en este sentido, la única práctica legítima en las escuelas, mientras que otras, tales como el cambio de lengua o el uso de variedades mixtas, se consideran perjudiciales para los niños.

Fragmento 5 (Participantes: DIRE1233: directora de una escuela de la zona de El Algarrobo)

DIRE1233: una cosa es que el docente traduzca... otra cosa es que sólo hable en wichi o esos que mezclan todo el tiempo $\backslash$ la traducción le sirve a los 
chicos porque así entienden \| la mezcla los confunde \al final no hablan bien ni una ni otra lengua \| eso no nos sirve $\backslash$ | para eso mejor solo en castellano $\backslash$ | si sólo hablan wichi al final no van a aprender nada \|

Así, el rol del docente indígena como traductor de otros o de sí mismo es coherente con las representaciones sociales que otorgan al docente indígena un lugar subordinado en el sistema escolar. En este rol, sus competencias lingüísticas quedan jerarquizadas en relación con las dinámicas hegemónicas en donde el castellano tiene un lugar casi exclusivo, patente en los materiales didácticos (sólo en esta lengua), en la estructura escolar (los docentes bilingües en las primeras etapas del sistema educativo) y en la organización escolar (los docentes bilingües en las aulas con estudiantes aborígenes exclusivamente).

Dice la directora de una escuela de la zona:

Fragmento 6 (Participantes: DIRE882c: Directora escuela 882c)

DIRE882c: Ellos [los aborígenes] nos lo cuestionan, pero nosotros como docentes... ellos nos cuestionan la falta de integración, pero la integración la hacen en cualquier momento.. en los recreos.. en la panadería en los juegos.. pero nosotros tenemos que trabajar así únicamente a la razón de lengua. Tenemos el auxiliar bilingüe para los chicos aborígenes. No tenemos tiempo_ porque como aprende el alumno blanco. Pierde tiempo mientras el indígena aprende en su lengua. El auxiliar le enseña con su lengua [a los indígenas]

Si, como mostramos, en El Algarrobo, la correlación entre grupos sociales y lengua otorga a los indígenas un lugar subordinado en las dinámicas sociales de la zona y restringe su acceso a las redes en donde los bienes simbólicos obtienen valor, sus competencias bilingües no parecen poder cuestionar esta distribución ni discutirle a los blancos su legitimidad en los procesos escolares que atañen a los miembros de sus comunidades.

\section{A modo de cierre}

La sociolingüística se ha preguntado desde hace años por la forma en que el lenguaje participa en la construcción de las jerarquías sociales, así como por la forma en que éste participa en la desigualdad social y en la reproducción del orden social (HELLER, 2001, 2007; RAMPTON, 2006). Algunas de sus corrientes, notablemente la sociolingüística interaccional y la antropología lingüística, han hecho hincapié en la necesidad de estudiar la forma de conexión entre las interacciones verbales locales y otros órdenes más amplios, en los cuales las desigualdades obtienen lógica y son sustentados a través de las ideologías. 
Según HELLER (2001), la sociolingüística debería también ser capaz de describir las formas de relación entre las consecuencias interaccionales inmediatas y las consecuencias a largo plazo, principalmente sobre el acceso de ciertos grupos a los recursos materiales y simbólicos; es decir, debería poder dar cuenta de las posibilidades de participación que tienen diferentes grupos en las redes, relaciones y actividades sociales en las cuales la circulación de esos recursos comunicativos es regulada, y en dónde éstos adquieren precios.

En el caso que aquípresentamos, las transformaciones políticas, económicas y sociales implican, tal y como intentamos mostrar, la movilidad de ciertos actores y la revalorización de ciertos recursos - por ejemplo, el conocimiento de las lenguas aborígenes que habilita el acceso a plazas de maestros bilingües. Estos cambios son resistidos por quienes no parecen dispuestos a ceder parte de los beneficios que obtenían en la situación anterior, por ejemplo, los "viejos maestros". Esta resistencia puede verse en el terreno de las lenguas, a través por ejemplo, de la forma negativa en que evalúan las competencias lingüísticas de los actores - de los "nuevos maestros", en este caso -, en la manera en que se va definiendo su lugar en el sistema escolar - como traductores del wichi al castellano, como mediadores en las clases impartidas por docentes blancos, o como puente hacia la castellanización de las poblaciones indígenas -, y por diversas formas de descalificación sobre las competencias profesionales de los jóvenes indígenas.

En estos cambios y estas resistencias, el lenguaje adquiere un rol importante. Se manifiesta, tal y como sugerimos, como un recurso clave en el control del acceso a ciertos bienes, como los que derivarían de la incorporación de los indígenas a las clases medias a través de la docencia. El lenguaje, sin embargo, no puede funcionar solo en ese lugar; se sostiene a través de representaciones sociales que mediatizan en las interacciones concretas los significados. Estas representaciones, parte del sentido común de un grupo o de una sociedad (RAITER, 2003), son clave para mantener un statu quo y son más resistentes a los cambios que los discursos, los cuales no consiguen muchas veces incidir en la profundidad del sentido social de las prácticas. El lenguaje consigue cambiar en lo que dice pero no consigue muchas veces cambiar en lo que significa.

En el caso que mostramos, la formación de maestros indígenas ha conseguido poner en escena nuevos actores, los cuales son legitimados desde ciertos discursos para el ejercicio de transformaciones importantes en las propuestas educativas de las minorías más excluidas de la Argentina. Sin embargo, estos nuevos actores deben hacer frente a viejas representaciones que operan en la exclusión social y que participan en su mantenimiento. Estas representaciones - por ejemplo sobre los indígenas como hablantes incompletos del castellano o como hablantes de mezclas - son funcionales en la lucha por recursos materiales y en el control del acceso a espacios simbólicos claves, como puede ser la escuela. 


\section{Referencias}

ACUÑA, L. De la castellanización a la educación intercultural bilingüe: sobre la atención de la diversidad lingüística en la Argentina. Revista de Historia Bonaerense, n. 24, p. 47-52, 2002.

Lenguas propias y lenguas prestadas en EIB. In: HIRSCH, S.; SERRUDO, A. (Comps.). La educación intercultural bilingüe en Argentina: identidades, lenguas y protagonistas. Buenos Aires: Noveduc, 2010. p. 321-258.

ARGENTINA. Ministerio de Educación, Ciencia y Tecnología. Resolución n $\mathbf{n}^{\mathbf{0}}$ 119/10 del Consejo Federal de Educación. La modalidad de educación intercultural bilingüe en el sistema educativo nacional. 2010. Disponible en: < http://www.me.gov.ar/consejo/ resoluciones/res10/119-10_01.pdf>. Acceso en: 10 mar. 2012.

BENGOCHEA, N.; SARTORI, M. F. La construcción de representaciones sobre las lenguas en constituciones y legislación argentina vigente. In: CONGRESO DE LA CÁTEDRA UNESCO DE LECTURA Y ESCRITURA, 2010, Buenos Aires. Actas... Buenos Aires: Universidad de General Sarmiento, 2010.

CAZDEN, C. B. E1 discurso del aula. Barcelona: Paidós, 1991.

CHACO. Cámara de diputados. Ley $\mathbf{n}^{\mathbf{0}}$ 3.258. Determina las normas que regirán a las comunidades indígenas. Crea la entidad autárquica denominada "Instituto del Aborigen Chaqueño” (I.D.A.CH.). Deroga la ley n. 970 “de facto” (régimen funcional y orgánico de la dirección del aborigen). Provincia del Chaco, 1987.

ECPI. Encuesta Complementaria de Pueblos Indígenas. Buenos Aires: INDEC, 20042005.

FERNÁNDEZ, C.; GANDULFO, C.; UNAMUNO, V. Lenguas indígenas y escuela en la Provincia del Chaco: el proyecto EGRESADOS. In: CONGRESO DE LA DELEGACIÓN ARGENTINA DE LA ASOCIACIÓN DE LINGÜÍSTICA Y FILOLOGÍA DE AMÉRICA LATINA, 1., 2012, La Plata. Actas... La Plata, 2012. (En prensa).

HELLER, M. Undoing the macro/micro dichotomy: ideology and categorisation in a linguistic minority school. In: COUPLAND, N.; SARANGI, S.; CANDLIN, C. N. (Eds.). Sociolinguistics and Social Theory. London: Longman, 2001. p. 212-234.

Distributed knowledge, distributed power: a sociolinguistics of structuration. Text

\& Talk - An Interdisciplinary Journal of Language, Discourse Communication Studies, v. 27, n. 5-6, p. 633-653, 2007. DOI: 10.1515/TEXT.2007.029

HIRSCH, S.; SERRUDO, A. (Comps.). La educación intercultural bilingüe en argentina: identidades, lenguas y protagonistas. Buenos Aires: Noveduc, 2010.

INDEC. Instituto Nacional de Estadística y Censos de Argentina. Censo Nacional de Población y Vivienda - 2001. Buenos Aires, 2001.

LÓPEZ, L. E.; KÜPER, W. La educación intercultural bilingüe en América Latina: balance y perspectivas. Cochabamba: H y P, 2004.

MALDONADO, A. La cuestión del bilingüismo en la EIB: teorías y realidades. In: CONGRESO DE LA SOCIEDAD ARGENTINA DE LINGÜÍSTICA, 11., 2008, 
Argentina. Actas... Argentina, 2008. Disponible en: < http://www.lenguas.unc.edu.ar/ aledar/hosted/xicongreso/simposio_y_coloquio/bilinguismo/maldonado.pdf $>$. Acceso en: 10 mar. 2012.

MARTIN-JONES, M.; SAXENA, M. Turn-taking, power asymmetries, and the positioning of bilingual participants in classroom discourse. Linguistics and Education, v. 8, n. 1, p. 105-123, 1996. DOI: 10.1016/S0898-5898(96)90008-X

MESSINEO, C.; CUNEO, P. Las lenguas indígenas de la Argentina: situación actual e investigaciones. Third International Workshop on (Semi) Numerical Techniques in Polynomial Equation Solving, in Honor of Joos Heintz's 60 ${ }^{\text {th }}$. Buenos Aires, 2006.

MILROY, J. Language ideologies and the consequences of standardization. Journal of Sociolinguistics, v. 5, n. 4, p. 530-555, 2001. DOI: 10.1111/1467-9481.00163

NOVARO, G. Pueblos indígenas y escuela: avances y obstáculos para el desarrollo de un enfoque intercultural. In: ARGENTINA. Ministerio de Educación, Ciencia y Tecnología (Ed.). Educación intercultural bilingüe en Argentina: sistematización de experiencias. Buenos Aires, 2004. p. 481-505.

PETZ, I. Pueblos originarios, estados provinciales y educación: un análisis comparativo de las políticas y prácticas educativas en contextos de diversidad sociocultural en Salta y Formosa. In: HIRSCH, S.; SERRUDO, A. (Comps.). La educación intercultural bilingüe en Argentina: identidades, lenguas y protagonistas. Buenos Aires: Noveduc, 2010. p. 45-70.

PRATT, M. L. Ojos imperiales: literatura de viajes y transculturación. México: Fondo de Cultura Económica, 2010.

RAITER, A. Lenguaje y sentido común. Buenos Aires: Biblos, 2003.

RAMPTON, B. Language in late modernity: interaction in an urban school. Cambridge: Cambridge University Press, 2006.

RIBEIRO, G. L. Tropicalismo e europeísmo: modos de representar o Brasil e a Argentina. In: FRIGERIO, A.; RIBEIRO, G. L. (Orgs.). Argentinos e brasileiros: encontros, imagens e estereótipos. Petrópolis: Vozes, 2002. p. 237-264.

SERRUDO, A. Indígenas en la escuela: representaciones y tensiones acerca de los docentes indígenas bilingües en Argentina. In: HIRSCH, S.; SERRUDO, A. (Comps.). La educación intercultural bilingüe en Argentina: identidades, lenguas y protagonistas. Buenos Aires: Noveduc, 2010. p. 255-272.

SINCLAIR, J.; COULTHARD, M. Towards an analysis of discourse. Oxford: O.U.P, 1975.

SLUTZKY, D. Situaciones problemáticas de tenencia de la tierra en Argentina. Buenos Aires: Ministerio de economía y producción, Secretaría de Agricultura, Ganadería, Pesca y Alimentos. Dirección de Desarrollo Agropecuario, PROINDER, 2008. (Serie estudios e investigaciones, n. 14).

TERRAZA, J. Algunos aspectos del desplazamiento lingüístico en comunidades aborígenes wichi. In: FERNÁNDEZ GARAY, A.; GOLLUSCIO, L. (Eds.). Temas de lingüística aborigen II. Buenos Aires: Instituto de Lingüística - FFyL, UBA, 2002. p. 245-262.

Grammaire du wichi: phonologie et morphosyntaxe. 2009. 295 f. Thèse (Doctorat en Linguistique) - Université du Québec à Montréal, Montréal, 2009. 
TRINCHERO, H. Los pueblos originarios en Argentina: representaciones para una caracterización problemática. Cultura y representaciones sociales, v. 4, n. 8, p. 111-139, 2010 .

UNAMUNO, V. Hablar correctamente es entender bien los términos que usan los blancos: hacia una descripción situada del plurilingüismo para una educación intercultural bilingüe en argentina. Revista Letras, Santa Maria, 2011. (En prensa).

Bilingüismo, formación docente e inserción laboral en la EIB. In: VARELA, L. (Ed.). Políticas del lenguaje. Cuadernos del Instituto de Políticas Culturales, Caseros, EDUNTREF, 2012. (En prensa).

UNAMUNO, V.; RAITER A. La educación intercultural bilingüe: discursos sobre los otros y nosotros. In: ZULLO, J.; RAITER, A. (Coords.). Esclavos de las palabras. Buenos Aires: EUDEBA, 2012. p. 125-160.

UNICEF. Los pueblos indígenas en Argentina y el derecho a la educación: situación socioeducativa de niñas, niños y adolescentes de comunidades rurales wichi y mbyá guaraní. Buenos Aires: Fondo de las Naciones Unidas para la Infancia - UNICEF, 2009.

VIDAL, A.; NERCESIAN, V. Estudio del léxico wichi (mataco-mataguaya): aportes al conocimiento de algunas situaciones de contacto y desplazamiento lingüístico en el Chaco argentino. Cuadernos Interculturales, v. 7, n. 12, p. 141-158, 2009.

VOLOSHINOV, V. El marxismo y la filosofía del lenguaje. Madrid: Alianza, 1992.

WOOLARD, K. A. La autoridad lingüística del español y las ideologías de la autenticidad y el anonimato. In: DEL VALLE, J. (Ed.). La lengua, ¿patria común? Ideas e ideologías del español. Madrid/Frankfurt: Iberoamericana; Vervuert, 2007. p. 29-142. (Colección: Lengua y Sociedad en el Mundo Hispánico, n. 17).

Les ideologies lingüístiques: una visió general d'un camp des de l'antropologia lingüística. Revista de Llengua i Dret, n. 49, p. 179-199, 2008.

ZIDARICH, M. Pareja vulnerable, si las hay: docente originario y docente no originario. In: HIRSCH, S.; SERRUDO, A. (Comps.). La Educación Intercultural Bilingüe en Argentina: identidades, lenguas y protagonistas. Buenos Aires: Noveduc, 2010, p. 223-254.

\section{Anexo A: Simbología de transcripción}

$>$ continuación del turno por el mismo participante

Secuencias tonales: descendente: \ascendente: /

pregunta con pronombre?

mantenida -

Pausas: breve | media || larga $<$ número de segundos $><0>$ ausencia de pausa Alargamiento silábico, según duración . .....

Encabalgamientos:

$=$ texto locutor $\mathrm{A}=$

=texto locutor $\mathrm{B}=$

Interrupciones: texto_

Intensidad: 
piano $\{(\mathrm{P})$ texto $\}$ pianissimo $\{(\mathrm{PP})$ texto $\}$

forte $\{(\mathrm{F})$ texto $\}$ fortissimo $\{(\mathrm{FF})$ texto $\}$

Tono alto $\{(\mathrm{A})$ texto $\}$ bajo $\{(\mathrm{B})$ texto $\}$

Tempo acelerado $\{(\mathrm{AC})$ texto $\}$ desacelerado $\{(\mathrm{DC})$ texto $\}$

Enunciados riendo $\{(@)$ texto $\}$

[+texto+] transcripción no alfabética

Comentarios [texto]

Fragmentos incomprensibles (según duración ): XXX | XXX XXX | XXX XXX XXX

Fragmentos dudosos $\{(?)$ texto $\}$

\section{Anexo B: Mapa de localización del Chaco}

Figura 1 - Provincia del Chaco

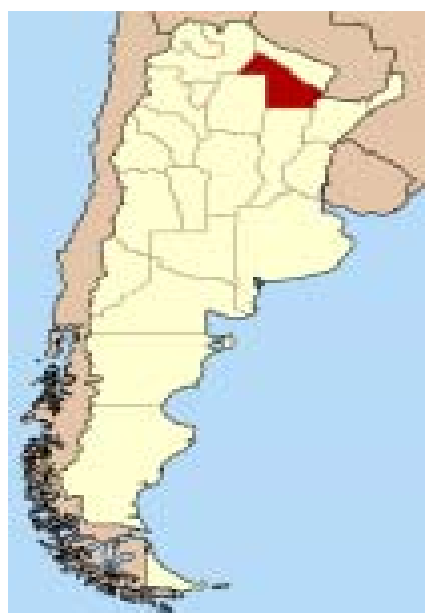

Fuente: $<$ http://portal.chaco.gov.ar/index.php $>$

Recebido em 01/06/2012

Versão final recebida em 11/09/2012/2012

Aceito em 31/10/2012 